\title{
Cutaneous neuroendocrine carcinoma
}

INSERM

\section{Source}

INSERM. (1999). Orphanet: an online rare disease and orphan drug data base. Cutaneous neuroendocrine carcinoma. ORPHA:79140

Cutaneous neuroendocrine carcinoma is a primary cutaneous cancer arising from a subset of skin neuroendocrine cells (Merkel cells, giving the name Merkel cell carcinoma (MCC)). 